\title{
Effect of caffeine on maximal strength and power in élite male athletes
}

\author{
B. H. Jacobson EdD, M. D. Weber MS, L. Claypool PhD and L. E. Hunt PhD \\ School of Health, Physical Education and Leisure, Oklahoma State University, Stillwater, Oklahoma, USA
}

\begin{abstract}
Computerized testing of 20 élite male athletes was performed to determine the effect of $7 \mathrm{mg} \mathrm{kg}^{-1}$ caffeine on strength and power of the knee extensors and flexors. Subjects received counterbalanced administrations of either caffeine or a placebo on two separate occasions. Peak torque $(T)$ was measured for knee extension $(E T)$ and flexion (FT) at angular velocities of $30^{\circ}, 150^{\circ}$ and $300^{\circ} \mathrm{s}^{-1}$. Additionally, performance for the first $125 \mathrm{~ms}(T A E)$ and power $(W)$ were recorded during $300^{\circ} \mathrm{s}^{-1}$. Testing sessions were held 1 week apart, at which time the placebo/caffeine administration was reversed. A $2 \times 2$ repeated measures analysis of variance supplemented with a Neuman-Keuls post hoc test showed the following - significant caffeinerelated increases $(P<0.05)$ for $E T$ at $30^{\circ} \mathrm{s}^{-1}, E T$ at $300^{\circ} \mathrm{s}^{-1}$, and $E T A E$, and $E W$ at $300^{\circ} \mathrm{s}^{-1}$. Dependent $t$-tests performed for pre- to post-test means showed significant changes for the caffeine group in $E T$ at $30^{\circ} \mathrm{s}^{-1}, F T$ at $30^{\circ} \mathrm{s}^{-1}, F T$ at $150^{\circ} \mathrm{s}^{-1}, E T$ at $300^{\circ} \mathrm{s}^{-1}, F T$ at $300^{\circ} \mathrm{s}^{-1}, E$ and $F T A E$, and $E W$ at $300^{\circ} \mathrm{s}^{-1}$. No significant effects were found for the placebo trial in any variable. It was concluded that caffeine can favourably affect some strength parameters in highly resistance-trained males. However, differences in subject fibre type, motivation and caffeine sensitivity need to be elucidated.
\end{abstract}

Keywords: Power, torque, athletes, ergogenic aid

Ingestion of large doses of caffeine has been reported by some of the nation's most élite contemporary athletes for the purpose of attaining an 'edge' in terms of competitive performance. Questionable sources have claimed that one athlete had consumed caffeine capsules equivalent to 41 cups of coffee (approximately $4100 \mathrm{mg}$ of caffeine) before and during competition ${ }^{1}$, while yet another athlete had admitted to ingesting an excess of $900 \mathrm{mg}$ of caffeine to obtain an ergogenic effect ${ }^{2}$. Such reports are not isolated. Indeed, for athletes who rely on strength and power such as weightlifters and those involved in track and field events, caffeine use has a long tradition $^{3}$. In an attempt to reduce the abuse of caffeine intake by amateur athletes, the International Olympic Committee and the National Collegiate

Address for correspondence: Bert $\mathrm{H}$. Jacobson EdD, Coordinator of Graduate Studies and Research, 103 PEC, Oklahoma State University, Stillwater, Oklahoma 74078, USA

(C) 1992 Butterworth-Heinemann Ltd 0306-3674/92/040276-05
Athletic Association in the USA now consider the excessive use of caffeine $\left(12 \mu \mathrm{g} \mathrm{ml}^{-1}\right.$ urine $)$ a violation of their standards ${ }^{4}$.

Speculation that caffeine may affect muscle function is based on the drug's actions on isolated nerve and muscle tissue ${ }^{5,6}$. Caffeine affects muscle tissue by direct intramuscular calcium ion manipulation ${ }^{7,8}$. Further, animal studies have shown that in the presence of caffeine, fatigue patterns differ between type I fibres and type II fibres, yet smaller muscles may not be affected to the same extent as larger muscles?.

As an ergogenic agent, caffeine may improve simple movement speed ${ }^{10}$ and long-term endurance ${ }^{11,12}$, but similar benefits have not been found for short, exhaustive forms of exercise ${ }^{13}$. Previous studies have failed to show that caffeine affects muscle functions such as strength and power.

In recent caffeine studies, $7 \mathrm{mg}$ of caffeine per kilogram body weight $\left(\mathrm{mg} \mathrm{kg}^{-1}\right)$ produced no significant effect on power or fatigue during cycle ergometry ${ }^{14}$. No significant differences in grip strength were found after subjects ingested 167, 324 and $500 \mathrm{mg}$ of caffeine ${ }^{15}$. A dose of $500 \mathrm{mg}$ caffeine produced no measurable differences in voluntary contractions, but resulted in significantly greater muscle tension with low-frequency electrical stimulation both before and after fatigue ${ }^{16}$. Furthermore, caffeine failed to produce any significant changes in isometric grip force production, motor unit activation, electromyographic signal or endurance 6 . Previous studies from this laboratory have found no significant changes in isokinetic strength after caffeine ingestion ( 300 and $600 \mathrm{mg}$ ) by untrained subjects $^{19}$. Similarly, $5 \mathrm{mg} \mathrm{kg}^{-1}$ caffeine yielded no significant changes in isokinetic strength tests at angular velocities of $30^{\circ}, 150^{\circ}$ and $300^{\circ} \mathrm{s}^{-9}$ (Reference 18). However, the authors recommended extending the protocol of their study by using a larger dose of caffeine. Other recommendations include the use of resistance-trained subjects ${ }^{17}$, controlling subject selection and the subject's nutritional state ${ }^{19}$.

Based on previous findings and recommendations, the purpose of this study was to determine the effect of $7 \mathrm{mg} \mathrm{kg}^{-1}$ caffeine on dynamic voluntary maximal strength and power output in highly resistancetrained athletes with similar $\left(<100 \mathrm{mg} \mathrm{day}^{-1}\right)$ caffeine intake. 


\section{Subjects}

Twenty male, intercollegiate Division I varsity team members in the sport of American football, with a mean(s.d.) age of 21(1.2) years, weight of $101(15) \mathrm{kg}$ and height of $187(9) \mathrm{cm}$ served as subjects for this study. All of the athletes had been competitively recruited by the university and awarded full academic scholarships based on their élite performance and abilities in the sport. Informed consent forms were signed in accordance with university policy. The subjects completed questionnaires addressing weekly caffeine consumption and years of resistance-training experience. Subjects with either high caffeine consumption $\left(>100 \mathrm{mg} \mathrm{day}^{-1}\right)$ or lacking sufficient $<2$ years) weight training experience were excluded from the study.

\section{Experimental design}

Testing sessions (pre- and post-test) were held on two separate occasions. At each session, data for knee flexion and extension were obtained using a Cybex II Dynamometer (Cybex Division of Lumex, Ronkonkoma, New York, USA) interfaced with a Cybex Data Reduction Computer. The dynamometer was gravity corrected and calibrated for range of motion (ROM) using an on-line electrogoniometer, and the lever arm of the apparatus was adjusted for consistent fit of the subject's dominant leg. The testing velocities, but not the number of repetitions, were consistent with that of Bond et al. ${ }^{18}$ For each testing session, the subject performed three repetitions at an angular velocity of $30^{\circ} \mathrm{s}^{-1}$, three repetitions at $150^{\circ} \mathrm{s}^{-1}$ and 15 repetitions at $300^{\circ} \mathrm{s}^{-1}$, for a total of 21 repetitions. One repetition consisted of moving the leg from a $105^{\circ}$ flexed position to full extension and back again. Table 1 presents the measured dependent variables and their abbreviations, the units, and the angular velocity of each variable.

For each of the three sets (three or 15 repetitions), data were collected for mean peak torque $(T)$ for knee extension $(E T)$ and flexion $(F T)$. In addition to these measurements, extension $(300 \mathrm{EW})$ and flexion power $(300 F W)$; extension (300ETAE) and flexion torque accelerated energy ( 300 FTAE) were recorded for the set of 15 repetitions at $300^{\circ} \mathrm{s}^{-1}$. Torque accelerated energy $(T A E)$, a unique feature of the testing apparatus, measures energy related to the range of motion during the first $125 \mathrm{~ms}$ of muscular contraction. As defined by the Cybex Corporation, TAE is a ROM-dependent product of torque and distance ${ }^{20}$

Table 1. Variable names, abbreviations, and units of measurement for each repetitive (Rep) trial at selected angular velocities (Vel)

\begin{tabular}{lccc}
\hline Rep $\times$ Vel movement & $\begin{array}{c}\text { Peak T } \\
(N m)\end{array}$ & $\begin{array}{c}\text { TAE } \\
\text { (Joules) }\end{array}$ & $\begin{array}{c}\text { Power } \\
\text { (Watts) }\end{array}$ \\
\hline $3 \times 30^{\circ} \mathrm{s}^{-1}$ Knee extension & $30 E T$ & - & - \\
$3 \times 30^{\circ} \mathrm{s}^{-1}$ Knee flexion & $30 F T$ & - & - \\
$3 \times 150^{\circ} \mathrm{s}^{-1}$ Knee extension & $150 E T$ & - & - \\
$3 \times 150^{\circ} \mathrm{s}^{-1}$ Knee flexion & $150 F T$ & - & - \\
$3 \times 300^{\circ} \mathrm{s}^{-1}$ Knee extension & $300 E T$ & $300 E T A E$ & $300 E W$ \\
$3 \times 300^{\circ} \mathrm{s}^{-1}$ Knee flexion & $300 F T$ & $300 F T A E$ & $300 F W$ \\
\hline
\end{tabular}

and may be measured in Joules (J) or Newton-metres $(\mathrm{Nm})$. An identical testing sequence was followed to avoid differences in fatigue, and 3-min rest periods were allowed between sets. Instructions for testing and encouragement to promote maximal effort were given before testing. Subjects were pre- and posttested on two separate occasions with random caffeine and placebo crossover administration.

\section{Drug administration}

Experimental drug dosage consisted of $7 \mathrm{mg} \mathrm{kg}^{-1}$ of caffeine which had been individually prepared according to each subject's body weight. Placebo consisted of $225 \mathrm{mg}$ of methylcellulose. Administration of caffeine and placebo followed a double-blind format with a random counterbalanced design. For the first testing session the subjects were given randomly $150 \mathrm{ml}$ orange juice and identical gelatin capsules containing either the experimental dose or the placebo. At the second testing session the random order of drug/placebo administration was reversed. Immediately after the pre-test, the subjects were given one of the prescribed doses and asked to sit quietly for a minimum of $1 \mathrm{~h}$ (Reference 21) before the post-test.

\section{Procedures}

To reduce any acquired or residual caffeine tolerance, the subjects were given written information concerning foods with caffeine as an ingredient and advised to abstain from these products for 1 week before testing. As a precaution against dissimilarities in nutritional status 22,23 , the subjects' diets were identical (carbohydrate $50 \%$, fat $30 \%$, protein $20 \%$ ) for 2 days before each testing session. Subjects were instructed to report to each testing session $8 \mathrm{~h}$ postprandial and to refrain from exercise for $48 \mathrm{~h}$ before testing. Testing was held at the same time of day (0700 hours) 1 week apart.

\section{Statistical design}

A $2 \times 2$ repeated measure analysis of variance was performed with the two levels of dose administration (caffeine and placebo) serving as the grouping factor and the two levels of testing (pre-test, post-test) serving as the trial factor ${ }^{24}$. A Neuman-Keuls post hoc test was used to ascertain the specific sites of significance. Probability level for significance was set at the $P<0.05$ level. Additionally, to account for differences in gain score directions, within-group paired $t$ tests were performed.

\section{Results}

As determined from the caffeine consumption questionnaire, the mean(s.d.) daily caffeine intake by the subjects was estimated at 72(25) mg. Subjects had been highly active in supervised resistance training for 5(1.8) years. Additionally, all of the subjects indicated that they had followed the directions of diet and caffeine intake as stipulated by the research. 
Table 2. Knee extension and flexion, pre- and post-test peak torque means(s.d.) for placebo and caffeine trials at angular velocities of $30^{\circ}, 150^{\circ}$ and $300^{\circ} \mathrm{s}^{-1}$

\begin{tabular}{|c|c|}
\hline Variables $(n=20)$ & Mean(s.d.) \\
\hline $\begin{array}{l}30 E T \text { pre-caffeine } \\
30 E T \text { post-caffeine } \\
30 E T \text { pre-placebo } \\
30 E T \text { post-placebo }\end{array}$ & $\begin{array}{l}292.4(59.2) \\
315.4(56.0) \\
297.3(54.8) \\
285.1(51.1)\end{array}$ \\
\hline $\begin{array}{l}\text { 30FT pre-caffeine } \\
30 F T \text { post-caffeine } \\
30 F T \text { pre-placebo } \\
30 F T \text { post-placebo }\end{array}$ & $\begin{array}{l}196.5(29.5) \\
207.2(32.2) \\
201.7(33.9) \\
203.3(34.2)\end{array}$ \\
\hline $\begin{array}{l}150 E T \text { pre-caffeine } \\
150 E T \text { post-caffeine } \\
150 E T \text { pre-placebo } \\
150 E T \text { post-placebo }\end{array}$ & $\begin{array}{l}244.5(36.6) \\
252.1(40.2) \\
236.6(38.0) \\
199.2(35.0)\end{array}$ \\
\hline $\begin{array}{l}150 F T \text { pre-caffeine } \\
150 F T \text { post-caffeine } \\
150 F T \text { pre-placebo } \\
150 F T \text { post-placebo }\end{array}$ & $\begin{array}{l}158.9(22.8) \\
167.6(27.8) \\
157.6(27.7) \\
159.1(21.0)\end{array}$ \\
\hline $\begin{array}{l}300 E T \text { pre-caffeine } \\
300 E T \text { post-caffeine } \\
300 E T \text { pre-placebo } \\
300 E T \text { post-placebo }\end{array}$ & $\begin{array}{l}155.1(36.5) \\
166.5(32.8) \\
158.7(27.4) \\
156.0(24.4)\end{array}$ \\
\hline $\begin{array}{l}300 F T \text { pre-caffeine } \\
300 F T \text { post-caffeine } \\
300 F T \text { pre-placebo } \\
300 F T \text { post-placebo }\end{array}$ & $\begin{array}{l}119.1(17.1) \\
126.1(21.9) \\
119.8(16.8) \\
212.3(14.3)\end{array}$ \\
\hline
\end{tabular}

Table 3. Knee extension and flexion pre- and post-test torque accelerated energy (TAE in Joules) and power ( $W$ in Watts) means(s.d.) for placebo and caffeine trials at $300^{\circ} \mathrm{s}^{-1}$

\begin{tabular}{lc}
\hline Variables $(n=20)$ & Mean(s.d.) \\
\hline 300ETAE pre-caffeine & $6368.3(1397.5)$ \\
300ETAE post-caffeine & $6905.5(1304.4)$ \\
300ETAE pre-placebo & $6480.3(1113.5)$ \\
300ETAE post-placebo & $6539.1(1016.4)$ \\
300FTAE pre-caffeine & $4676.3(770.8)$ \\
300FTAE post-caffeine & $5183.3(948.9)$ \\
300FTAE pre-placebo & $4766.9(878.8)$ \\
300FTAE post-placebo & $4923.1(715.9)$ \\
& \\
300EW pre-caffeine & $598.9(134.4)$ \\
300EW post-caffeine & $633.6(130.3)$ \\
300EW pre-placebo & $621.2(133.5)$ \\
300EW post-placebo & $597.3(105.1)$ \\
300FW pre-caffeine & $452.7(80.8)$ \\
300FW post-caffeine & $478.1(91.7)$ \\
300FW pre-placebo & $462.5(82.3)$ \\
300FW post-placebo & $454.2(67.6)$ \\
\hline
\end{tabular}

Table 2 and Table 3 illustrate pre- and post-test means and standard deviations for all variables tested.

The $2 \times 2$ repeated measures analysis of variance combined with the post hoc procedure revealed significant $(P<0.05)$ between-group differences (Table 4 and Table 5) for four of the ten variables: ET at $30^{\circ} \mathrm{s}^{-1} ; E T$ at $300^{\circ} \mathrm{s}^{-1} ; E T A E$; and EW at $\left.300^{\circ} \mathrm{s}^{-1}\right)$. Significant $(P \leq 0.05)$ within-group (pre- to post-test) differences were noted in eight variables for the caffeine group: $E T$ at $30^{\circ} \mathrm{s}^{-1} ; F T$ at $30^{\circ} \mathrm{s}^{-1} ; F T$ at $150^{\circ} \mathrm{s}^{-1} ; E T$ at $300^{\circ} \mathrm{s}^{-1} ;$ FT at $300^{\circ} \mathrm{s}^{-1} ;$ ETAE; FTAE;
Table 4. Knee extension and flexion post-test peak torque (Nm) means(s.d.) and gain scores for placebo and caffeine trials at angular velocities of $30^{\circ}, 150^{\circ}$ and $300^{\circ} \mathrm{s}^{-1}$

\begin{tabular}{lcccc}
\hline Variables $(n=20)$ & $\begin{array}{c}\text { Placebo } \\
\text { mean(s.d.) }\end{array}$ & $\begin{array}{c}\text { Gain } \\
\text { score }\end{array}$ & $\begin{array}{c}\text { Caffeine } \\
\text { mean(s.d.) }\end{array}$ & $\begin{array}{c}\text { Gain } \\
\text { score }\end{array}$ \\
\hline $\begin{array}{l}\text { Extension (30ET) } \\
\quad 3 \times 30^{\circ} \mathrm{s}^{-1}\end{array}$ & $285.1(51.1)$ & -12.2 & $315.4(56.0)$ & $22.6^{*}+$ \\
$\begin{array}{c}\text { Flexion }(30 \mathrm{FT}) \\
3 \times 30^{\circ} \mathrm{s}^{-1}\end{array}$ & $203.3(34.2)$ & 1.6 & $207.2(32.2)$ & $10.7+$ \\
$\begin{array}{c}\text { Extension }(150 E T) \\
\quad 3 \times 150^{\circ} \mathrm{s}^{-1}\end{array}$ & $237.7(34.1)$ & 1.0 & $252.1(40.2)$ & 7.4 \\
$\begin{array}{c}\text { Flexion }(150 \mathrm{FT}) \\
3 \times 150^{\circ} \mathrm{s}^{-1}\end{array}$ & $159.1(21.0)$ & 1.6 & $167.6(27.8)$ & $8.6+$ \\
$\begin{array}{c}\text { Extension }(300 E T) \\
3 \times 150^{\circ} \mathrm{s}^{-1}\end{array}$ & $156.0(24.4)$ & -2.8 & $166.5(32.8)$ & $11.4^{*} \dagger$ \\
$\begin{array}{c}\text { Flexion }(300 \mathrm{FT}) \\
3 \times 150^{\circ} \mathrm{s}^{-1}\end{array}$ & $121.3(14.3)$ & 1.5 & $126.1(21.9)$ & $7.0 \dagger$ \\
\hline
\end{tabular}

* $P \leq 0.05$ between group significance

$+P \leq 0.05$ within group significance

Table 5. Knee extension and flexion post-test TAE (J) and power (Watts) means(s.d.) and gain scores for placebo and caffeine trials at $300^{\circ} \mathrm{s}^{-1}$

\begin{tabular}{|c|c|c|c|c|}
\hline Variables $(n=20)$ & $\begin{array}{c}\text { Placebo } \\
\text { mean(s.d.) }\end{array}$ & $\begin{array}{l}\text { Gain } \\
\text { score }\end{array}$ & $\begin{array}{c}\text { Caffeine } \\
\text { mean(s.d.) }\end{array}$ & $\begin{array}{l}\text { Gain } \\
\text { score }\end{array}$ \\
\hline $\begin{array}{l}\text { Extension (300ETAE) } \\
\quad 3 \times 300^{\circ} \mathrm{s}^{-1} \text { (Joules) }\end{array}$ & $6539(1060)$ & 58.7 & 6905(1304) & $537.1^{*}+$ \\
\hline $\begin{array}{l}\text { Flexion }(300 F T A E) \\
\qquad 3 \times 300^{\circ} \mathrm{s}^{-1} \text { (Joules) }\end{array}$ & $4923(716)$ & 156.1 & $5183(950)$ & $508.0 t$ \\
\hline $\begin{array}{l}\text { Extension (300EW) } \\
\quad 3 \times 300^{\circ} \mathrm{s}^{-1} \text { (Watts) }\end{array}$ & $597(105)$ & -22.9 & $633.6(130)$ & $34.8 * t$ \\
\hline $\begin{array}{l}\text { Flexion }(300 \mathrm{FW}) \\
\qquad 3 \times 300^{\circ} \mathrm{s}^{-1} \text { (Watts) }\end{array}$ & $454(67)$ & -8.3 & $478(91)$ & 25.4 \\
\hline
\end{tabular}

* $P \leq 0.05$ between group significance

$+P \leq 0.05$ within group significance

and $E W$ at $300^{\circ} \mathrm{s}^{-1}$. No significant changes occurred in any of the placebo trials.

\section{Discussion}

Studies have demonstrated that, under certain conditions, caffeine may enhance muscle force production and endurance ${ }^{16,25}$. To date, no studies have reported increases in voluntary strength and/or power resulting from caffeine. The results of our study are more consistent with caffeine studies conducted in vitro ${ }^{25,26}$ than those done in vivo ${ }^{6,16-18}$. Our data show significant $(P \leqslant 0.05)$ caffeine-related strength and power increases and possible reductions in post-test strength loss in some variables.

Studies in vitro have demonstrated that absorption of caffeine by the muscle tissue ${ }^{5}$ potentiates isometric twitch tension in stimulated isolated muscle tissue ${ }^{9,25}$ after both rest and fatigue ${ }^{25}$. The effects of caffeine on muscle tissue were attributed to: (1) rapid release of calcium ions from the sarcoplasmic reticulum $(\mathrm{SR})^{8}$; (2) decrease in the rate of calcium ion uptake ${ }^{7}$; (3) increase in the calcium ion permeability of the sarcolemma ${ }^{27} ;(4)$ loss of membrane integrity by rapid dilation of SR tubules ${ }^{28}$; (5) increased intracellular 
cyclic adenosine $5^{\prime}$ monophosphate (AMP) levels ${ }^{29}$. Contractures present after caffeine treatment are absent in calcium ion-depleted muscle tissue ${ }^{30}$. Perhaps the most noted difference between in vitro and in vivo studies is that caffeine doses found to be effective in vitro are generally of greater relative magnitude than those obtained in oral, in vivo, administration.

Much of the disagreement in caffeine-related investigations results from differences in experimental protocol ${ }^{19}$. In an attempt to explain our results, several variations from preceding investigations must be addressed. Following the recommendations by previous authors ${ }^{18}$, whose equipment and protocol we followed closely, a larger dose of caffeine $\left(7 \mathrm{mg} \mathrm{kg}^{-1}\right)$ was used in this study. Likewise, Williams and associates ${ }^{6,14}$ used similar doses of caffeine on two separate occasions but failed to find significant changes in isometric strength, time to fatigue, or power. In contrast to our study, they studied pedalling at maximal velocities for $15 \mathrm{~s}$ on a cycle ergometer under moderate load ${ }^{14}$.

The caffeine-related effects found in our study may be due to the nature and background of our subjects with respect to resistance training and athletic competition. With the exception of one study that used aerobically trained subjects, no other study revealed the training background of their subjects. Given the resistance-type protocol used in assessing strength and power, our subjects' extensive involvement and acquaintance with resistive training may have enhanced the ability to exert maximal effort in each trial.

Caffeine reduces the ability of the SR to store and accumulate calcium ions, and depresses calcium ion release by inhibiting reaccumulation ${ }^{9}$. In animal studies, fatigue patterns of type I muscle fibres are more dramatically affected by caffeine than in type II fibres, presumably because of the sparser SR common to type I fibres 9 . This phenomenon has not been investigated in human caffeine studies ${ }^{22}$.

Athletes, those involved in anaerobic compared to those involved in aerobic sports, have differences in fibre-type ratios. Additionally, these athletes possess fibre types different from non-athletes ${ }^{31}$. If the animal models can be applied to humans, it is conceivable that the effects of caffeine may differ in fatigue patterns between those individuals with unbalanced fibre type ratios and those with balanced ratios. In examining our results, it appears that in certain tests a fatigue factor was more prominent in the placebo group than in the caffeine group. However, muscle fibre-type ratio was not examined in this study so one can only speculate on this phenomenon.

It has been documented that specific nutrients may inhibit the effects of caffeine ${ }^{23}$. Diet has been related to carbohydrates and aerobic activity but has not been investigated in anaerobic activity. By controlling the subject's diet for 2 days before testing, possible metabolic interferences may have been reduced. Other than regulating caffeine intake, no methods of diet control were mentioned in other similar investigations.

In conclusion this study shows that it is possible for caffeine ingestion to give rise to some changes in voluntary strength and power output. Furthermore, the experimental doses show that the effects of caffeine may be magnified and the experimental doses may be more indicative of those consumed by some athletes for the purpose of enhancing athletic performance. Although none of our subjects had any adverse reactions to the drug, we recommend that additional investigations exploring the effect of doses more common to abuse should also consider the health of the subjects. Some subjects reported that they felt as if they had performed better following caffeine. Perhaps the stimulating effects of caffeine serve to alter perceived exertion, not unlike results found for treadmill running ${ }^{19}$. Finally, the possibility that caffeine may delay muscular fatigue may be an area worth exploring.

We suggest with some caution that $7 \mathrm{mg} \mathrm{kg}^{-1}$ of caffeine may enhance strength and power parameters in resistance-trained athletes. It should be noted that extreme levels of caffeine are not only illegal in sanctioned competition, but may present potential health risks during competition, such as exacerbated dehydration and fatigue ${ }^{32}$, delirium, anxiety, memory impairment and hallucinations ${ }^{33}$.

\section{References}

1 Bosworth B, Reilly B. The Boz, Confessions of a Modern Anti-Hero. New York: Doubleday, 1988.

2 Telander R. The big enchilada. Sports Illustrated 24 April 1989; 70: 40-49.

3 Brooks GA, Fahey TD Exercise Physiology: Human Bioenergetics and its Application. New York: John Wiley and Sons, 1984.

4 Bell AJ, Doege CT. Athletes' use and abuse of drugs. Physician Sportsmed 1986; 15: 99-101.

5 Axelrod J, Reichtenthal J. The fate of caffeine in man and a method for its estimation in biological material. J Pharmacol Exp Ther 1953; 107: 519-23.

6 Williams JH, Barnes WS, Gadberry WL. Influence of caffeine on force and EMG in rested and fatigued muscle. Am J Phys Med 1987; 66: 169-83.

7 Weber A. The mechanism of the action of caffeine on sarcoplasmic reticulum. J Gen Physiol 1968; 52: 760-772.

8 Weber A, Herz R. The relationship between caffeine contracture of intact muscle and the effect of caffeine on reticulum. J Gen Physiol 1968; 68: 766-72.

9 Brust M. Fatigue and caffeine effects in fast-twitch and slow-twitch muscles of the mouse. Pflugers Arch 1976; 267: 189-200.

10 Jacobson BH, Edgley BM. Effects of caffeine on simple reaction time and movement time. Aviat Space Environ Med 1987; 58: 1153-7.

11 Costill DL, Dalsky GP, Fink WJ. Effects of caffeine ingestion on metabolism and exercise performance. Med Sci Sports Exerc 1978; 10: 155-8.

12 Ivy JL, Costill D, Fink WJ et al. Influence of caffeine and carbohydrate feedings on endurance performance. Med Sci Sports Exerc 1979; 11: 6-11.

13 Butts NK, Crowell D. Effect of caffeine ingestion on cardiorespiratory endurance in men and women. Res $Q$ Exerc Sport 1985; 46: 301-5.

14 Williams JH, Signorile JF, Barnes WS, Henrich TW. Caffeine, maximal power output and fatigue. Br J Sports Med 1988; 22: $132-4$.

15 Bugyi GJ. The effects of moderate doses of caffeine on fatigue parameters of the forearm flexor muscles. Am Corr Ther J 1980; 34: 49-53.

16 Lopes JM, Aubier M, Jardim J et al. Effect of caffeine on skeletal muscle function before and after fatigue. $J$ Appl Physiol 1983; 54: 1303-5.

17 Jacobson $\mathrm{BH}$, Edwards SW. Influence of two levels of caffeine on maximal torque at selected velocities. I Sports Med Phys Fitness 1991; 31: 147-53. 
18 Bond V, Gresham K, McRae J et al. Caffeine ingestion and isokinetic strength. Br J Pharmacol 1986; 20: 135-7.

19 Tarnopolski MA, Atkinson SA, Macdougall JD et al. Physiological responses to caffeine during endurance running in habitual caffeine users. Med Sci Sports Exerc 1989; 21 418-24.

20 Cybex: Computerized Isolated Joint Testing. Ronkonkoma, New York: Cybex, 1983.

21 Leonard TK, Watson RD, Mohs ME. The effects of caffeine in various body systems: a review. J Am Diet Assoc 1987; 87: 1048-53.

22 Bucci LR. Nutritional ergogenic aids. In: Hickson JF, Wolinsky I, eds. Nutrition in Exercise and Sports. Boca Raton, Florida: CRC Press, 1989.

23 Weir J, Noakes TD, Myburgh K, Adams B. A high carbohydrate diet negates the metabolic effects of caffeine during exercise. Med Sci Sports Exerc 1987; 19: 100-105.

24 Brogan AR, Kutner MH. Comparative analyses of pretestpost-test research designs. The American Statistician 1980; 34: 229-32.

25 MacIntosh BR, Barbee RW, Stainsby WN. Contractile response to caffeine of rested and fatigued skeletal muscle. Med Sci Sports Exerc 1981; 13: 95.
26 Connett RJ, Ugol LM, Hammack, MJ, Hays ET. Twitch potentiation and caffeine contractures in isolated rat soleus muscle. Comp Biochem Physiol 1983; 74C: 349-54.

27 Kavaler F, Anderson TW, Fisher VJ. Sarcolemmal site of caffeine's inotropic action on ventricular muscle of the frog. Circ Res 1978; 42: 285-90.

28 Huddart H, Abram RG. Modification of excitation-contraction coupling in locust skeletal muscle induced by caffeine. J Exp Zool 1969; 171: 49-58.

29 Butcher RW, Sutherland EW. Adenosine $3^{\prime}, 5^{\prime}$ phosphate in biological material. J Biol Chem 1962; 237: 1244-55.

30 Fujino M, Fujino S. Die beziehung zwischen CoffeinKontraktur und Calcium am Froschskeletemuskel. Pflugers Arch Ges Physiol 1964; 278: 478-86.

31 Fox EL, Bowers RW, Foss ML. The Physiological Basis of Physical Education and Athletics, 3rd edn. Philadelphia: Saunders College Publishing, 1988.

32 United States Olympic Committee on Substance Abuse. Questions and Answers. Colorado Springs: USOC, 1987.

33 Stillner V, Popkin MK, Pierce CM. Caffeine induced delirium during prolonged competitive stress. Am J Psychiatry 1978; 135: 855-8.

\section{Book reviews}

\section{Advances in Ergometry}

N. Bachl, T. E. Graham and $H$. Lollgren, eds

London: Springer-Verlag, 1991, DM 86.00, $513 \mathrm{pp}$

Every conference organizer feels the need to commemorate the event to which he has devoted so much effort by publishing the proceedings. On occasion, the result is an outstanding success - an example which comes to mind is the proceedings of the conference on the Marathon published as volume 301 of the Annals of the New York Academy of Sciences in 1977. More commonly, however, published conference proceedings are a failure, and there are several reasons for this. Keynote papers or reviews by the invited speakers are almost invariably and inevitably identical to reviews published elsewhere. The abstracts of oral communications or poster sessions offer the opportunity to see some new material, but again, you can be sure that any data of substance will appear in one of the scientific journals.

What then is the value of conference proceedings, and does this volume offer anything of value to the reader? I see two main reasons for reading (as opposed to publishing) conference proceedings. One is speed of publication. Since the refereeing process for papers is considerably shortened, or perhaps omitted altogether, it is possible for the publication time to be shortened to no more than a few months rather than the 1-2 years which now seems to be normal for journals. Second, the less stringent refereeing of conference papers means that the reader can see data that would otherwise remain unpublished. Keynote speakers often take the opportunity to introduce preliminary or inconclusive results and to speculate in a way that would not be considered acceptable by most journals and their referees. Much of the information that appears in abstract form in conference proceedings never appears as a full paper, and so would be lost to the scientific community.

This volume fails on the first count. We are not told the date of the conference (the Sixth International Seminar on Ergometry), but the publication date is 1991, and the most recent date that I could find in the reference lists is 1989 , so I suspect that

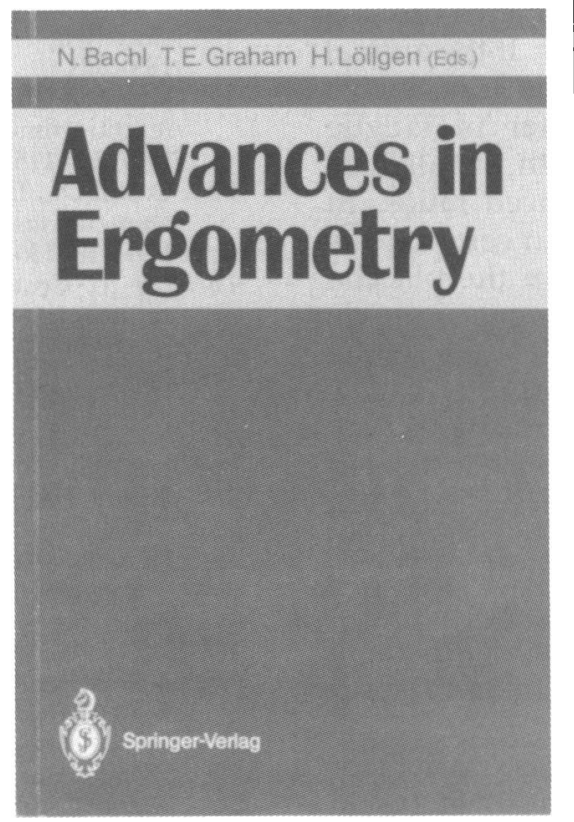
The review papers are generally disappointing. An outstanding exception to this is the review on lactate metabolism by Terry Graham - although this is not so different from other reviews by the same author, it deserves to be read by everyone working in this area of exercise physiology. This chapter, with its explicit criticism of the anaerobic threshold concept, sits oddly with the large part of the remainder which is concerned with the minutiae of the conduct and interpretation of this test.

Another redeeming feature of this book is the considerable amount of information from scientists working in Europe, and especially in Germany, who do not normally publish in English language journals. This reveals two things - first, many of us must be quite unaware of much of the work that is being done, and second, the converse is also true. Much effort is being devoted to investigating problems which I thought had been resolved many years ago. Although it is good to see established ideas challenged by repetition, and either confirmed or refuted, it is depressing not to see any acknowledgement of the large body of published data which exists. The difficulty of communication is also evident in the quality of the English translation, which makes some of the papers hard to follow.

In conclusion, then, it is difficult to know whether to recommend this book or not, but it is probably worth looking at for Terry Graham's review alone.

R. J. Maughan PhD, Science Editor, BJSM 